\title{
Antimicrobial Activity of Biosynthesized Silver Nanoparticles Compared to Standard Antibiotics Used in ORL Infections
}

\author{
ALINA ANDREEA TISCHER (TUCUINA) ${ }^{1 \#}$, DELIA BERCEANU VADUVA ${ }^{1}$, NICOLAE BALICA $^{1 *}$, ALINA HEGHES ${ }^{2 *}$, \\ ADELINA CHEVERESAN ${ }^{1}$, MIRELA VOICU ${ }^{2}$, DELIA HORHAT ${ }^{1}$, HORATIU CRISTIAN MANEA ${ }^{3}$, MARIOARA POENARU ${ }^{1}$ \\ ${ }^{1}$ Victor Babes University of Medicine and Pharmacy, Faculty of Medicine, 2 Eftimie Murgu Sq., 300041, Timisoara, Romania \\ 2Victor Babes University of Medicine and Pharmacy, Faculty of Pharmacy, 2 Eftimie Murgu Sq., 300041, Timisoara, Romania \\ ${ }^{3}$ Victor Babes University of Medicine and Pharmacy, Department of ENT, 2 Eftimie Murgu Sq.,300041, Timisoara, Romania
}

In recentyears, bacterial infections in hospitals have grown particularly due to the development of antibiotic resistance. Recent research targets the discovery of new antibiotics that exhibit broad spectrum of action without adverse effects or minimizing adverse effects. In this study, the activity of biosynthesized silver nanoparticles against three bacteria commonly found in infectious diseases in the ORL sphere was evaluated. The recorded data revealed an activity comparable to that of the standard antibiotics used in these types of infections, with the observation that the activity of the nanoparticles could also be observed in the particular cases of antibiotic resistance.

Keywords: green silver nanoparticles, antibiotics, resistance, bacterial strains

Multiplication of infections in hospitals due to treatmentresistant bacteria in which the usual antibiotics are no longer effective has become an alarming problem and a real danger to human health. The complex mechanism involved in the development of antibiotic resistance, even in the case of new generations, has not been fully elucidated. This requires additional studies to optimize diagnosis, find new therapies without side-effects or with minimal side effects and / or reduce abusive drug use [ 1 , 2]. Biofilms are microbial formations wrapped in a polymeric matrix, with the major components exopolysaccharides. Microbes grow and develop in this matrix due to nutritional resources and protection against environmental factors. Biofilms are sources of pathogenic organisms that trigger disease. They are directly involved in the occurrence of ORL disorders, such as otitis media and otolaryngeal infections [3]. Pseudomonas aeruginosa, is a gram negative bacteria, a pathogen responsible for the occurrence of infections (sepsis, endocarditis, etc.) that has become resistant to frequently used antibiotic treatment, responsible for high rates of morbidity and mortality. Haemophilus influenzae is a gram-negative bacterium thattriggers respiratory tract complications, and is known as a respiratory and invasive pathogen. The main diseases caused by $H$. influenzae in children are pneumonia, meningitis and bacteremia, and in adults are pneumonia, acute otitis media, acute sinusitis and acute exacerbation of chronic bronchitis[4]. Streptococcus pneumoniae is a gram-positive bacteria that colonizes the mucosal surfaces of the human upper respiratory tract and is the main cause of otitis media, community pneumonia, sepsis and meningitis [5].

The chemical synthesis methods applied to the metal nanoparticles most often require the use of toxic reagents, solvents, chemical coating agents, and special synthetic

conditions that lead to increased production costs and environmental pollution. An inexpensive and safe alternative is that of nanoparticle biosynthesis [6]. Silver nanoparticles have captured the researchers' attention due to the remarkable properties of silver ions which in metallic form are inert, butin ionized form they become very reactive [7].

This study aimed testing the antimicrobial activity of biosynthetized silver nanoparticles compared to antibiotics used for infections produced by Pseudomonas aeruginosa, Haemophilus influenzae and Streptococcus pneumoniae by different methods, namely: a) preclinical testing-on bacterial strains by disk diffusion method and anti-biofilm activity and b) clinical testing-classic antibiotics on biological samples originated from current clinical activity.

\section{Experimental part}

\section{Materials and methods}

The reagents used in the present study were of analytical grade, acquired from Sigma Aldrich, Germany and utilized as received without any other supplementary purification. Green silver nanoparticles were obtained as previously described byAndor etal.[8]. Briefly, to an aqueous rosemary leaves extract (RAE) - recognized both as a reducing and stabilizing agent- was added an aqueous solution of $\mathrm{AgNO}_{3}$ ( $1 \mathrm{mM}$ ) and the reaction mixture was inserted in an orbital shaker (away from light, for two days, $250 \mathrm{rpm}$, at room temperature), then purified and utilized in the in vitro experiments.

Preclinical testing. Green silver nanoparticles obtained with an aqueous extract of rosemary leaves were tested at different concentrations $(0.1-10 \mu \mathrm{g} / \mathrm{mL})$ on three bacterial strains. Reference strains are presented in table 1.

\begin{tabular}{|l|l|l|}
\hline Bacterial species & Code & Producer \\
\hline Pseudomonas aeruginosa & ATCCTM 27853 TM & Thermo Fischer Scientific \\
\hline Streptococcus pneumoniae & ATCCTM 27336 & Thermo Fischer Scientific \\
\hline Haemophilus infiuenzae & ATCCTM 49144 & Thermo Fischer Scientific \\
\hline
\end{tabular}

Table 1

REFERENCE BACTERIAL STRAINS UTILIZED IN THE PRESENT STUDY

*email: heghes.alina@umft.ro

\# Authors with equal contribution 


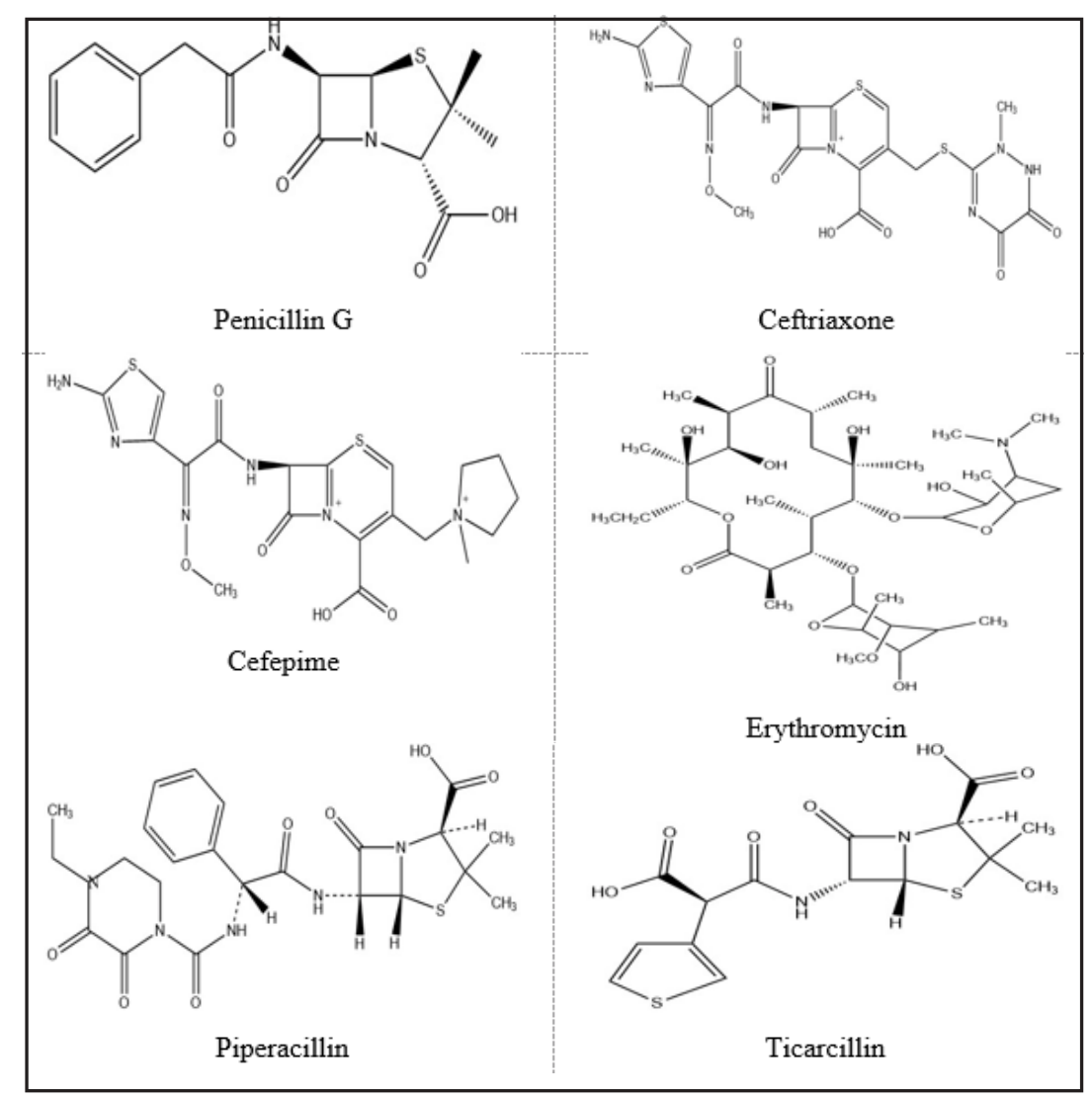

Fig. 1

Chemical structures of antibiotics utilized as positive controls in the experiments

prior to antimicrobial administration. Bacterial isolation was performed on Columbia agar with blood and Chocolat (Sanimed, Romania) agar and the plates were incubated at $37^{\circ} \mathrm{C}$. Api NH (bioMerieux, France) kits were used to identify Haemophilus influenzae strains while for the rest of the isolated species the Vitek 2 Compact automatic analyser (bioMerieux, France) was employed. Sensitivity testing for anti-infectious chemotherapies was performed by diffusion and E-tests (AB Biodisk, Sweden) according to the CLSI standard. (CT0167B conc. $75 \mu \mathrm{g}$ ) disks (Thermo-Fischer Scientific) and the negative control, was represented by the blank paper disk treated with the solvent employed in the experiments.

\section{Anti-biofilm activity}

The colorimetric test is often utilized in order to evaluate the activity of different compounds on biofilm. The steps required to apply the technique are as follows: (i) $10^{6} / \mathrm{mL}$ bacterial strain are cultured in 96-well plates are, (ii) various concentrations of RAE AgNPs are added after $24 \mathrm{~h}$, (iii) the plates are incubated with test samples for $4 \mathrm{~h}$ at $37^{\circ} \mathrm{C}$, (iv) the wells are washed, dried and treated with crystal violet aqueous solution, and (v) final washings and absorbance reading at $595 \mathrm{~nm}$ using an ELISA reader. The percentage inhibition of biofilm activity was calculated by the formula presented in the literature [10].

\section{Clinical testing}

Biological samples originated from current clinical activity, were harvested according to the internal protocol

\section{Results and discussions}

The antibacterial activity of silver nanoparticles compared to classic antibiotics used as positive control was evaluated on three bacterial strains. The Pseudomonas aeruginosa and Streptococcus pneumoniae were significantly influenced by silver nanoparticles. The zone of inhibition diameters are noted in table 2 .

RAE AgNPs were utilized in order to inhibit the activity of biofilms. In this research, the assessment of nanoparticles on biofilms activity in the human pathogens $P$. aeruginosa, $S$. pneumoniae and $H$. influenzae was evaluated by in vitro methods. The test strains were treated with various concentrations of RAE_AgNPs ( 0.1 to $10 \mu \mathrm{g} /$ $\mathrm{mL}$ ) and data showed that, green silver nanoparticles prevented the activity of biofilms, significant even from a concentration of $1 \mu \mathrm{g} / \mathrm{mL}$, as can be seen in the figure 2 .

Treatment of Pseudomonas aeruginosa for $24 \mathrm{~h}$ with 1 $\mu \mathrm{g} / \mathrm{mL}$ of RAE_AgNPs decreased biofilm activity by almost

\begin{tabular}{|c|c|c|c|}
\hline $\begin{array}{l}\text { Positive control/Test } \\
\text { compounds }\end{array}$ & $\begin{array}{l}\text { Pseudomonas } \\
\text { aeruginosa }\end{array}$ & $\begin{array}{l}\text { Streptococcus } \\
\text { pneumoniae }\end{array}$ & $\begin{array}{l}\text { Haemophilus } \\
\text { influenzae }\end{array}$ \\
\hline Penicillin & $16 \mathrm{~mm}$ & $6 \mathrm{~mm}$ & $12 \mathrm{~mm}$ \\
\hline Cefepime & $14 \mathrm{~mm}$ & $15 \mathrm{~mm}$ & $15 \mathrm{~mm}$ \\
\hline Ceftriaxone & $12 \mathrm{~mm}$ & $16 \mathrm{~mm}$ & $15 \mathrm{~mm}$ \\
\hline Erythromycin & $10 \mathrm{~mm}$ & $11 \mathrm{~mm}$ & $8 \mathrm{~mm}$ \\
\hline Piperacillin & $8 \mathrm{~mm}$ & $15 \mathrm{~mm}$ & $9 \mathrm{~mm}$ \\
\hline Tícarcillin & $7 \mathrm{~mm}$ & $15 \mathrm{~mm}$ & $7 \mathrm{~mm}$ \\
\hline RAE AgNPs & $19 \mathrm{~mm}$ & $16 \mathrm{~mm}$ & $14 \mathrm{~mm}$ \\
\hline
\end{tabular}

Table 2

ZONE OF INHIBITION (mm) OF POSITIVE CONTROLS AND TESTED SAMPLES AGAINST THREE BACTERIAL STRAINS 


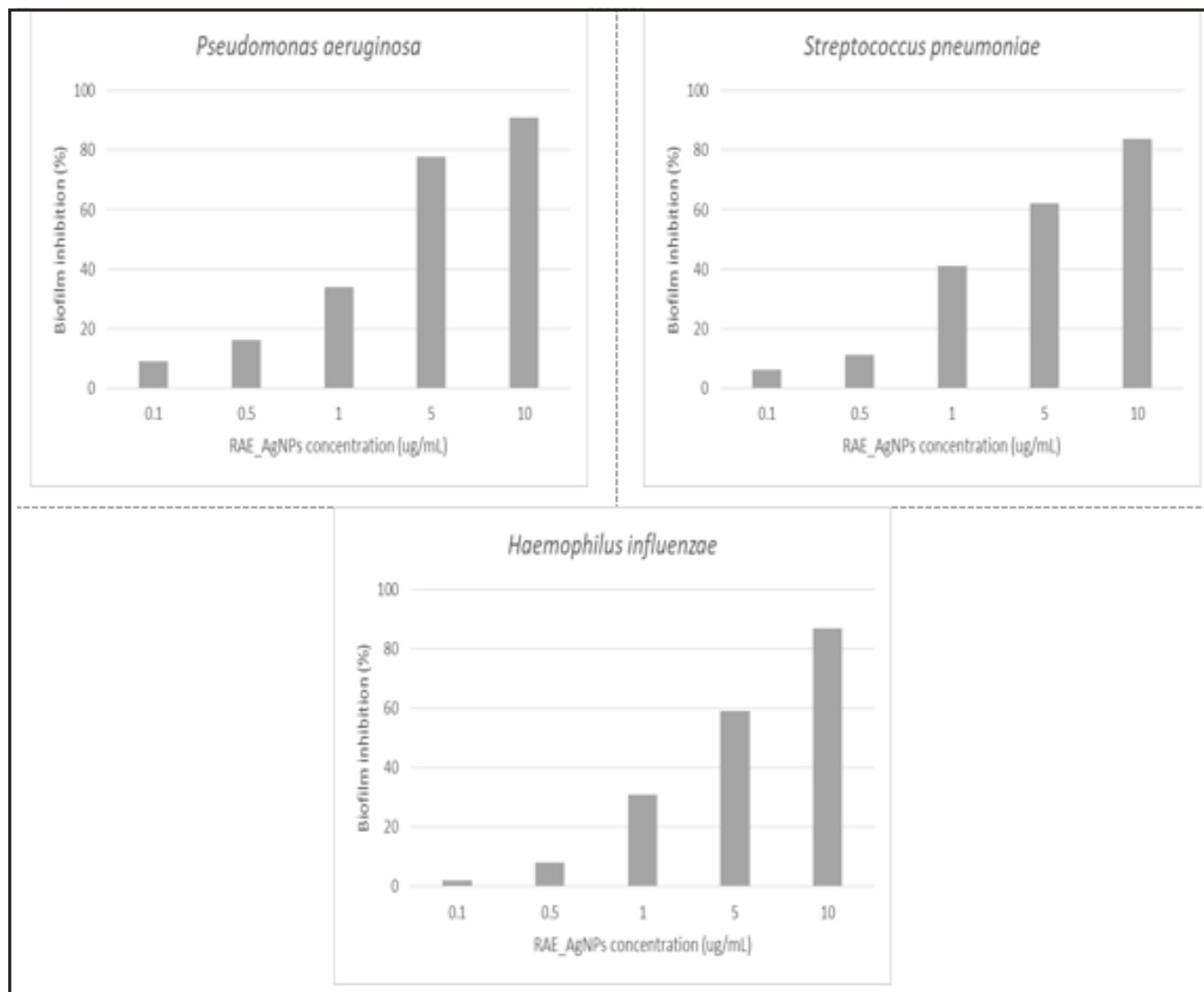

Fig. 2. Activity of different concentrations of RAE_AgNPS on biofilm inhibition

$40 \%$ while in case of a higher concentration, $5 \mu \mathrm{g} / \mathrm{mL}$ the percentage of inhibition is almost $80 \%$. In case of evaluation of the Streptococcus pneumoniae and Haemophilus influenzae biofilm activity, inhibition values were close, around $60 \%$ at a concentration of $5 \mu \mathrm{g} / \mathrm{mL}$, respectively about $80 \%$ at a concentration of $10 \mu \mathrm{g} / \mathrm{mL}$.

In the case of clinical trials, only positive controls were used. 20 bacterial strains were identified, including: 13 Streptococcus pneumoniae, 4 - Haemophilus influenzae and 3 - Pseudomonas aeruginosa. Each of the three identified batteries showed resistance to the antibiotics tested as follows: 4 Streptococcus pneumoniae strains showed resistance to penicillin, but they kept their sensitivity to ceftriaxone and cefepime; 7 Streptococcus pneumoniae strains were resistant to erythromycin and one Pseudomonas aeruginosa strain was resistant to piperacillin and ticarcillin.

Gurunathan et al. tested silver nanoparticles in combination with antibiotics on both gram positive bacteria and gram negative bacteria. They noticed a more pronounced increase in the association of nanoparticles with ampicillin against Gram-negative negative bacteria Pseudomonas aeruginosa and Shigella flexneri; and vancomycin association for Gram-positive bacteria Staphylococcus aureus and Streptococcus pneumoniae [11]. In another recent study, Kamble and Shinde tested the biofilm inhibition activity of green silver nanoparticles obtained with Curcuma longa and observed promising activity against biofilm formation [12]. The interest in finding new active compounds against resistant bacteria, obtained by safe and cheap methods without the use of harmful chemical reagents, remains a topical one.

\section{Conclusions}

The antibacterial activity of silver nanoparticles obtained by biosynthesis with an aqueous extract of rosemary leaves has been tested against strains of $P$. aeruginosa, $H$. influenzae and $S$. pneumoniae known to be resistant to several antibiotics. An increased antibacterial activity of RAE_AgNPs with higher efficacy against $P$. aeruginosa has been observed. Also, RAE AgNPs have been shown to be effective inhibitors of biofilm formation even at low concentrations.

\section{References}

1. FRANCI, G., FALANGA, A., GALDIERO, S., PALOMBA, L., RAI, M., MORELLI, G., GALDIERO, M. Molecules 20, 2015, p. 8856.

2. HORHAT, R.M., VLAICU, B., BAGIU, R., PUTNOKY, S., BAGIU, I., HORHAT, D.I., SZUHANEK, C. et al. Rev. Chim.(Bucharest), 69, no.6, 2018, p. 1371.

3. KRITHIGA, N., JAYACHITRA, A. Eur. J. Biomed. Pharm. Sci. 5(1), 2018, p. 324.

4. TRISTRAM, S., JACOBS, M.R., APPELBAUM, P.C. Clin. Microbiol. Rev. 20(2), 2007, p. 368.

5. WEISER, J.N., FERREIRA, D.M., PATON, J.C. Nat. Rev. Microbiol. 16(6), 2018, p. 355.

6. GOPINATH, V., PRIYADARSHINI, S., LOKE, M.F., ARUNKUMAR, J., MARSILI, E., MUBARAK ALI, D. ARAB. J. Chem. 10, 2017, p. 1107.

7. PINZARU, I., CORICOVAC, D., DEHELEAN, C., MOACA, E.A., MIOC, M., BADERCA, F. et al. Food Chem. Toxicol. 111, 2018, p. 546.

8. ANDOR, B., TISCHER (TUCUINA), A.A., BERCEANU-VADUVA, D., LAZUREANU, V., CHEVERESAN, A., POENARU, M. Rev. Chim.(Bucharest), 70, no.3, 2019, p. 781.

9. POPOVICI, R.A., VADUVA, D., PINZARU, I., DEHELEAN, C.A., FARCAS, C.G., DORINA CORICOVAC, D. et al. Exp. Ther. Med. 2019. DOI: 10.3892/etm.2019.7635

10. WEI, G.X., CAMPAGNA, A.N., BOBEK, L.A. J. Antimicrob. Chemother. 57, 2006, p. 1100.

11. GURUNATHAN, G., HAN, J.W., KWON, D.-N., KIM, J.-H. Nanoscale Res. Lett. 9, 2014, p. 373.

12. KAMBLE, S.P., SHINDE, K.D. Pharm. Nanotechnol. 6(3), 2018, p. 165.

\section{Manuscript received:9.10.2018}

